97-384 Wigglesworth, Gillian (Macquarie U.). An investigation of planning time and proficiency level on oral test discourse. Language Teaching (London), 14, 1 (1997), 85-106.

The inclusion of planning time in semi-direct oral interaction tests adds considerably to the overall length of the test, and it is important to be clear that the increase in length is justified by the language outcome. Previous research has shown that the effect of planning time in second language can differentially influence the resultant discourse, with planned discourse eliciting more complex language on a range of measures. However, where planning time has been provided it has generally been a substantial amount of time (ten minutes or more), and in a second language classroom situation, rather than a testing situation. Where planning time is provided in an oral interaction test it is generally limited to one or two minutes. In this study planning time was manipulated as a variable in a trial administration of a semi-direct test. Discourse analytic techniques were then used to determine the nature and/or significance of differences in the elicited discourse across the two conditions in terms of complexity and accuracy. In addition, candidates were divided into highproficiency versus low-proficiency groups. The findings suggest that, for the high-proficiency candidates, planning time may improve accuracy on some measures where the cognitive load of the task is high, but that this effect does not extend to the lowproficiency candidates.

\title{
Teacher education
}

\section{7-385 LeBlanc, Leona B. (Florida State U.). Testing French teacher certification can- didates for speaking ability: an alternative to the OPI. The French Review (Champaign, IL), 70, 3 (1997), 383-94.}

Many state departments of education require that the French teachers demonstrate their skills and competencies by passing a test in order to be certified to teach in $\mathrm{K}$ (indergarten) through to 12 . One such test is the Florida Initial Teacher Subject Area Test (ITSAT), which includes an assessment of speaking ability. A discussion of this test, which was developed as an alternative to the Oral Proficiency Interview (OPI), is presented. In addition, the paper includes the results of a reliability study on this speaking test and suggests various applications of this assessment tool.

\section{7-386 Pacek, Dorota (U. of Birmingham). Lessons to be learnt from negative evaluation. ELT Journal (Oxford), 50, 4 (1996), 335-42.}

In-service training (INSET) programmes which introduce novel approaches to teaching often seem exciting and eye-opening while the course lasts. However, the programmes do not always take account of what will happen when the course participants return to their daily routines. This article describes the post-course evaluation of an INSET programme for Japanese secondary school teachers of English, which found that the communicative approach introduced in the course was not implemented by a number of the participants. This reluc- tance to innovate seems to stern from differences between British and Japanese educational and cultural traditions. It is suggested that INSET courses should therefore present a range of traditional and modern approaches to English as a foreign language methodology, so that teacher trainees can select those which are most appropriate in their particular circumstances. Such courses should be more sensitive to the participants' cultural and educational backgrounds, and provide a cognitive element from the start.

\section{7-387 Robinson, John and Heyes, Irene (Manchester Metropolitan U.). Conflicting models of teacher training in multi-ethnic classrooms: journal of a mentor. Language, Culture and Curriculum (Clevedon), 9, 2 (1996), 120-32.}

The paper examines part of a journal kept by a mentor (i.e. an experienced teacher supervising the teaching practice of a student teacher) in a multi- ethnic classroom in Britain. The mentor was an expert in the bilingual education of ethnic minority children, and the journal describes difficulties she 
encountered with a multilingual (UrduPunjabi-English) student teacher, in particular the reluctance of the student teacher to use any language other than English. It is argued that the difficulties that such students have in appreciating the potentials of bilingual education reflect conflicting models of teacher training held by the schools and the training colleges, the former emphasising classroom management and subject knowledge, and the latter equality. It is argued also that a further shift towards exclusively school-based teacher education will not be conducive to more equal treatment of ethnic minorities.

\section{7-388 Sengupta, Sima and Nicholson, Suzy (U. of Hong Kong). On-line and ongo- ing: teacher development through TeleTeach. ELT Journal (Oxford), 50, 4 (1996), 290-302.}

This article describes the aims of an evolving teaching resources database, called TeleTeach, which is part of a computer-based teacher support network, called TeleNex. The TeleTeach component in TeleNex is integrally linked with all the other components. It is claimed that the interactive nature of the network makes the database, and the whole network, unique. The purpose of Tele Teach is to build an ongoing partnership between teachers and teacher educators, and to help create a collaborative culture across schools. This article describes the ways in which its unique features may contribute towards building an electronic community of reflective teachers, and suggests that the relationship between teaching materials and a teacher's professional development is potentially complementary. It also suggests that teachers need to be fully engaged in shaping this database if its potential is to be fully exploited.

\section{7-389 Thornbury, Scott (Internat. House, Barcelona). Teachers research teacher talk. ELT Journal (Oxford), 50, 4 (1996), 279-88.}

This article describes an in-service training project designed to raise trainees' awareness, through the analysis of transcriptions of teaching sequences, of the degree of communicativeness in their classroom interactions. The presence or absence of such features of communicative classroom talk as referential questions, feedback on content, wait time, and learner-initiated interaction, are used as 'bottom-up' markers of communicative, content-driven, teacher-student interaction. Trainees' analyses showed evidence of growing awareness of their non-communicative ritualised teaching behaviours, awareness which, at least in some cases, resulted in improved classroom practice. 